CLINICAL STUDY

\title{
Higher maternal TSH levels in pregnancy are associated with increased risk for miscarriage, fetal or neonatal death
}

\author{
$\mathrm{N}_{\text {Benhadi }}{ }^{1}$, W M Wiersinga ${ }^{1}$, J B Reitsma ${ }^{2}$, T G M Vrijkotte ${ }^{3}$ and G J Bonsel ${ }^{3}$ \\ Departments of ${ }^{1}$ Endocrinology and Metabolism, ${ }^{2}$ Clinical Epidemiology, Biostatistics and Bioinformatics and ${ }^{3}$ Social Science, Academic Medical Centre of \\ the University of Amsterdam, Meibergdree 9, 1105 AZ Amsterdam, The Netherlands
}

(Correspondence should be addressed to N Benhadi; Email: n.benhadi@amc.uva.nl)

\begin{abstract}
Background: To examine the relationship between maternal TSH and free thyroxine $\left(\mathrm{FT}_{4}\right)$ concentrations in early pregnancy and the risk of miscarriage, fetal or neonatal death.

Method: Cohort study of 2497 Dutch women. TSH, $\mathrm{FT}_{4}$, and thyroid peroxidase antibodies concentrations were determined at first booking. Child loss was operationalized as miscarriage, fetal or neonatal death. Women with overt thyroid dysfunction were excluded.

Results: Twenty-seven cases of child loss were observed. The mean TSH and $\mathrm{FT}_{4}$ level in the women with child loss was $1.48 \mathrm{mU} / \mathrm{l}$ and $9.82 \mathrm{pmol} / \mathrm{l}$ compared with $1.11 \mathrm{mU} / \mathrm{l}$ and $9.58 \mathrm{pmol} / \mathrm{l}$ in women without child loss. The incidence of child loss increased by $60 \%(\mathrm{OR}=1.60(95 \%$ confidence interval (CI): 1.04-2.47)) for every doubling in TSH concentration. This association remained after adjustment for smoking, age, parity, diabetes mellitus, hypertension, previous preterm deliveries, and previous preterm stillbirth/miscarriage (adjusted odds ratio $=1.80(95 \% \mathrm{CI}: 1.07-3.03)$ ). This was not true for $\mathrm{FT}_{4}$ concentrations $(\mathrm{OR}=1.41$ (95\% CI: $\left.0.21-9.40) ; P=0.724\right)$.

Conclusion: In a cohort of pregnant women without overt thyroid dysfunction, the risk of child loss increased with higher levels of maternal TSH. Maternal $\mathrm{FT}_{4}$ concentrations and child loss were not associated.
\end{abstract}

European Journal of Endocrinology $160985-991$

\section{Introduction}

Thyroid hormones are vital for the development of the brain both during fetal and early postnatal life. Impaired maternal thyroid hormone availability may induce irreversible brain damage with consequent neurological abnormalities (1-8). So far, only the effects of subclinical and overt hypo- and hyperthyroidism on pregnancy outcome have been studied. Overt maternal hypothyroidism in the first trimester is associated with preterm delivery and fetal death (9). Haddow et al. (1999) reported that children of women whose TSH levels were increased during mid-term of pregnancy had a slight but significant reduction in intelligence quotient score between 7 and 9 years of age when compared with infants of euthyroid women (10). Allan et al. (2002) showed that TSH levels above $6 \mathrm{mU} / \mathrm{l}$ are significantly associated with a higher frequency of stillbirth (11). Women with RTH, (high free thyroxine $\left(\mathrm{FT}_{4}\right)$ levels accompanied with normal or slightly elevated TSH levels) have a higher rate of miscarriage (12). In a study of Casey et al. (2007) there were no significant adverse effects on perinatal outcome in women with maternal hypothyroxinemia (low $\mathrm{FT}_{4}$ levels accompanied with normal TSH levels) in the first half of their pregnancy (13).
From the evidence in cases with overt hypo- or hyperthyroidism, we would expect both low and high TSH and $\mathrm{FT}_{4}$ to be associated with miscarriage, fetal or neonatal death (child loss). The purpose of the present study was to examine the association between maternal levels of TSH, $\mathrm{FT}_{4}$, thyroid peroxidase antibodies (TPO$\mathrm{Ab}$ ) measured in pregnancy, and subsequent child loss, excluding women with known thyroid disease or overt hypo- or hyperthyroidism.

The study was carried out using data from native Dutch pregnant women without known or clinical thyroid disease, who participated in a large populationbased cohort study (Amsterdam Born Children and their Development (ABCD) study, Amsterdam 2003-2004). Other ethnic groups participating in this study were excluded from the present analysis, because of the significant differences in serum TSH and in pregnancy outcome that exist between the various ethnic groups (14).

\section{Materials and methods}

\section{Subjects}

Our study was nested within a prospective cohort study of pregnant women from the ABCD study (14). The main objective of the ABCD study is to examine 
differences in pregnancy outcome, focusing on ethnic background, maternal lifestyle factors, and psychosocial conditions on the outcome of the pregnancy and the baby's health. The ABCD study is a collaborative effort of the Municipal Health Services and all hospitals and midwife practices in Amsterdam, the Netherlands. All pregnant women living in the city of Amsterdam were invited to participate at their first visit to an obstetric caregiver between January 2003 and March 2004. Of 12377 pregnant women invited, 8266 women agreed to participate (response rate $67 \%$ ). These women filled out a questionnaire including questions about social demographic characteristics and ethnic background. Four thousand two hundred and sixty seven women gave additional informed consent for blood collection during their first visit that took place on average in the 13 th week of gestation. The study protocol was approved by the medical ethnical committees of all Amsterdam hospitals and the Registration Committee of Amsterdam, and participants gave their written informed consent.

\section{Baseline characteristics}

All pregnant women received a pregnancy questionnaire at their home address 2 weeks after their first antenatal visit. The questionnaire contained demographic, health history, medication, and lifestyle questions, all from existing validated sources. All approached women were asked to return the pregnancy questionnaire by prepaid mail. A written reminder was sent 2 weeks after the initial mailing.

Smoking status during pregnancy, parity, age, and body mass index (BMI) were determined from the self reported information. In this study, we recoded smoking as a dichotomous question for current smoking (yes/no), regardless of the amount of cigarettes smoked daily. Parity was recoded in a categorical variable $(0,1$, and $2+)$. BMI was based on the length and weight of the mother before pregnancy. Alcohol was not included in the analysis of our study in view of the very low levels of alcohol use among the Dutch pregnant women in our study population.

Hypertension (no, pre-existent and gestational hypertension) and diabetes mellitus (no, pre-existent and gestational diabetes) were based on self-reported information from the questionnaire and completed by information from the national obstetric registry (Perinatal Registration Centre of the Netherlands) (14). This registry was linked to the $\mathrm{ABCD}$ data by probabilistic record linkage (15). These data were gathered by a trained health care provider.

We also recorded women who had a preterm delivery in previous pregnancies and previous miscarriage or stillbirth. In our stillbirth/miscarriage variable, we included intra-uterine deaths as well. All these data were based on the information from trained health care providers from the national obstetric registry (Perinatal
Registration Centre of the Netherlands) (14). Validation has shown close to perfect results for these variables.

\section{Assays}

For our study serum $\mathrm{TSH}, \mathrm{FT}_{4}$, and antibodies against TPO (TPO-Ab) were assayed. TSH (reference range (RR), 0.34-5.60 mU/l) and $\mathrm{FT}_{4}$ concentration (RR, 7.5-21.1 pmol/l) were measured in serum by means of access immunoanalyzer of Beckman Coultier Inc. The inter-assay variation for TSH was $5.0 \%$ and for $\mathrm{FT}_{4}$ the inter-assay variation was $3.1-5.0 \%$. Antibodies against TPO (TPO-Ab) were determined by ELISA ELIZEN TG Ab (E-CK-96), Zentech, Luik, Belgium. A TPO-Ab concentration above $80 \mathrm{kU} / \mathrm{l}$ was considered as positive. The inter-assay variation was $13.4 \%$.

Overt hyperthyroidism was defined as having a TSH concentration below $0.34 \mathrm{mU} / \mathrm{l}$ in combination with $\mathrm{FT}_{4}$ concentration above the upper limit of $21.1 \mathrm{pmol} / \mathrm{l}$. Overt hypothyroidism was defined as a TSH above the $5.60 \mathrm{mU} / \mathrm{l}$ upper limit in combination with a $\mathrm{FT}_{4}$ below the lower limit of $7.5 \mathrm{pmol} / \mathrm{l}$.

\section{Outcomes}

The occurrence of miscarriage, fetal death or neonatal death (child loss) was determined from three overlapping sources; i) the National Midwife Registry, ii) the National Obstetricians Registry and iii) the National Neonatal Registry. Miscarriage was defined as death of the fetus occurring before 22 weeks of gestation. Fetal death and neonatal death were defined according to existing standards (fetal death: death occurring from 22 weeks of gestation until delivery; neonatal death: death from 0 to 7 days after delivery). Fetal death includes stillbirth and intra-uterine deaths in our cohort.

\section{Statistical analysis}

Differences in demographic and clinical characteristics were analyzed in a descriptive way. Logistic regression models were built to explore the relationship between $\mathrm{TSH}, \mathrm{FT}_{4}$ concentrations determinants, and the occurrence of miscarriage, fetal death, and neonatal death in more detail. Restricted also known as natural cubic splines ( 4 knots) were used to examine the functional relationship between TSH and $\mathrm{FT}_{4}$ levels in relation to the outcome $(17,18)$. Based on these graphical analyses, we used a log transformation (to the power of two) as this clearly improved the linear relationship between $\mathrm{TSH}$ and $\mathrm{FT}_{4}$. In addition to the univariate analysis, we also build a multivariate model containing the following potential confounders: current smoker (yes/no), mother's age (continuous), parity (categorical: $0,1,2+$ ), hypertension (no, pre-existent and gestational hypertension), diabetes mellitus (no, pre-existent, gestational diabetes), previous preterm deliveries 
(yes/no), previous stillbirth/miscarriages (yes/no) and TPO-Ab presence (yes/no) with TPO-Ab concentration below $80 \mathrm{kU} / \mathrm{l}$ or more as positive. The modeling strategy was the same whether examining the relationship between levels of TSH or $\mathrm{FT}_{4}$ with child loss. $P$ values of $<0.05$ were considered statistically significant.

All statistical analysis was performed using the Statistical Package of Social Sciences and problem solutions (SPSS version 15.0).

\section{Results}

The initial number of native Dutch women within the ABCD cohort giving informed consent for blood sampling was 2684. From this starting cohort, we excluded 116 women in whom blood sampling occurred after the 27 th week of gestation (third trimester). Of the remaining, we excluded 29 women who gave birth to twins. We also excluded 18 women with overt hypo- or hyperthyroidism defined as $\mathrm{TSH}>5.6 \mathrm{mU} / \mathrm{l}$ in combination with $\mathrm{FT}_{4}<7.5 \mathrm{pmol} / \mathrm{l}$ and $\mathrm{TSH}<0.34 \mathrm{mU} / \mathrm{l}$ in combination with $\mathrm{FT}_{4}>21.1 \mathrm{pmol} / \mathrm{l}$ respectively. Of the 2521 women who remained in the study, we excluded another 24 with missing TSH values, leaving 2497 women in our analysis (Fig. 1).

Our study population of 2497 Dutch pregnant women had a mean age of 32.0 (s.D. $=4.0$ ) years. In $60 \%$ of the women this was their first pregnancy and $32 \%$ their second. Of all women 9.2\% smoked during their pregnancy. There were $129(5 \%)$ women with a TSH concentration below $0.34 \mathrm{mU} / \mathrm{l}$ and $11(0.5 \%)$ with a TSH value above $5.6 \mathrm{mU} / \mathrm{l}$. $\mathrm{A} \mathrm{FT}_{4}$ concentration below $7.5 \mathrm{pmol} / \mathrm{l}$ was seen in 94 women (4\%) and there were no women with a $\mathrm{FT}_{4}$ value above the $21.1 \mathrm{pmol} / \mathrm{l}$ in our study cohort. The overall prevalence of elevated TPO-Ab (concentration above $>80 \mathrm{kU} / \mathrm{l}$ ) was $5.8 \%$ (146/2497; see Table 1).

TSH and $\mathrm{FT}_{4}$ levels were negatively correlated (Pearson's $r=-0.375, \quad P<0.001)$. The TPO-Ab concentration was positively associated with TSH

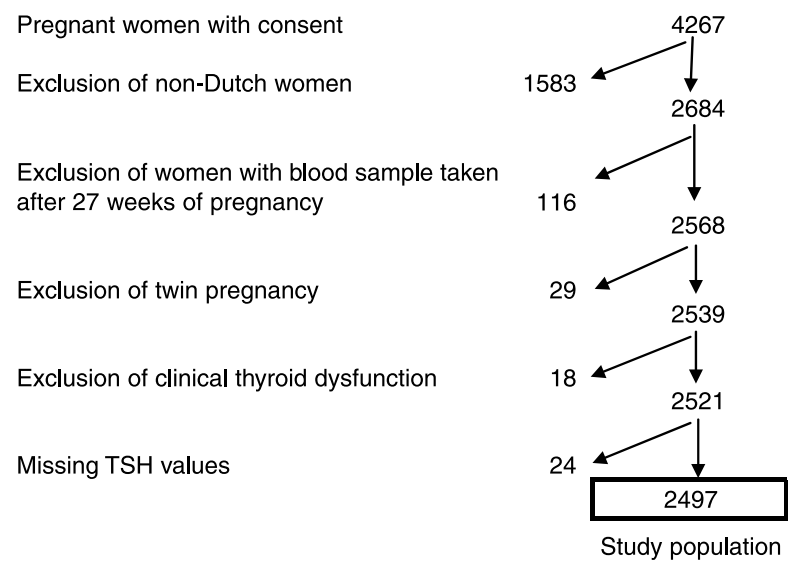

Figure 1 Flow chart of study population.
Table 1 Characteristics of study participants.

\begin{tabular}{|c|c|c|}
\hline & & Percent (\%) \\
\hline$n$ & 2497 & \\
\hline \multicolumn{3}{|l|}{ Age (year) } \\
\hline Mean ( \pm s.D.) & 32 & $( \pm 4.0)$ \\
\hline$<20$ & 18 & 0.7 \\
\hline $20-29$ & 526 & 21 \\
\hline $30-39$ & 1850 & 74 \\
\hline $40+$ & 54 & 2.2 \\
\hline \multicolumn{3}{|l|}{ Parity } \\
\hline 0 & 1485 & 60 \\
\hline 1 & 784 & 31 \\
\hline $2+$ & 174 & 7 \\
\hline Smoking & 230 & 9.2 \\
\hline \multicolumn{3}{|c|}{ Gestational age at booking (weeks) } \\
\hline Mean ( \pm S.D. $)$ & 13 & $( \pm 2.42)$ \\
\hline \multicolumn{3}{|l|}{ DM } \\
\hline Pre-existent & 8 & 0.3 \\
\hline Gestational diabetes & 2 & 0.1 \\
\hline \multicolumn{3}{|l|}{ Hypertension } \\
\hline Pre-existent & 71 & 2.8 \\
\hline Gestational hypertension & 230 & 9.2 \\
\hline \multicolumn{3}{|l|}{ Previous stillbirth/miscarriage } \\
\hline Yes & 465 & 19 \\
\hline \multicolumn{3}{|l|}{ Previous preterm delivery } \\
\hline Yes & 32 & 1.3 \\
\hline \multicolumn{3}{|l|}{ TSH (mU/l) } \\
\hline Median (p25-75) & 1.20 & $(0.81-1.76)$ \\
\hline \multicolumn{3}{|l|}{ Free $\mathrm{T}_{4}(\mathrm{pmol} / \mathrm{l})$} \\
\hline Median (p25-75) & 9.55 & $(8.77-10.43)$ \\
\hline \multicolumn{3}{|l|}{ TPO-Ab presence $(\mathrm{kU} / \mathrm{l})$} \\
\hline$<80$ & 2352 & 94 \\
\hline $80-300$ & 54 & 2.2 \\
\hline $300-600$ & 37 & 1.5 \\
\hline $600+$ & 54 & 2.2 \\
\hline \multicolumn{3}{|c|}{ Gestational age at deliveries (weeks) } \\
\hline$<22$ & 16 & 0.6 \\
\hline $22-31$ & 20 & 0.8 \\
\hline $32-36$ & 114 & 4.6 \\
\hline $37+$ & 2325 & 94 \\
\hline \multicolumn{3}{|l|}{ Child loss $(n=27)$} \\
\hline Miscarriage $^{\mathrm{a}}$ & 11 & $41 \%$ \\
\hline Fetal death ${ }^{a}$ & 10 & $37 \%$ \\
\hline Neonatal death ${ }^{\mathrm{a}}$ & 6 & $22 \%$ \\
\hline
\end{tabular}

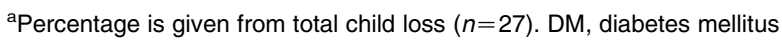

$(r=0.322 ; P<0.001)$ and negatively with $\mathrm{FT}_{4}$ concentration $(r=-0.065 ; P<0.001$, two tailed). The median TSH value in women without TPO-Ab was 1.17 (IQR: 0.80-1.70) and 2.16 (IQR: 1.27-3.38) in women with $\mathrm{TPO}-\mathrm{Ab}$ in serum. The median $\mathrm{FT}_{4}$ concentration was 9.59 (IQR: 8.81-10.43) and 9.00 (IQR: 8.16-10.17) respectively. This difference between the TPO-Ab positive and negative women was significant for both the TSH and the $\mathrm{FT}_{4}$ levels $(P<0.001)$.

In our cohort 11 women had a miscarriage $(0.5 \%)$. There were 20 very premature $(<32$ weeks) deliveries $(0.8 \%)$, of which eight died $(0.3 \%), 114$ premature deliveries (32-36 weeks), (4.6\%), of which two died $(0.8 \%)$ and 2325 mature deliveries $(93 \%)$, of which six died $(0.1 \%)$, (Table 2). In total there were 27 miscarriages, fetal or neonatal deaths. There were three women who ended their pregnancy because the child 
Table 2 Logistic regression results examining the association between TSH (panel A) and free thyroxine ( $\mathrm{FT}_{4}$; panel $\mathrm{B}$ ) levels and other factors with child loss (miscarriage, fetal or neonatal death).

\begin{tabular}{|c|c|c|c|c|c|c|}
\hline \multirow[b]{2}{*}{ Factors } & \multirow[b]{2}{*}{$\begin{array}{l}\text { Child loss } \\
(n=27)\end{array}$} & \multirow[b]{2}{*}{$\begin{array}{l}\text { Alive after } 7 \\
\text { days }(n=2465)\end{array}$} & \multicolumn{2}{|c|}{ Univariate analysis } & \multicolumn{2}{|c|}{ Multivariate analysis } \\
\hline & & & OR $(95 \% \mathrm{Cl})^{\mathrm{b}}$ & $P$ value & OR $(95 \% \mathrm{Cl})$ & $P$ value \\
\hline \multicolumn{7}{|l|}{$\begin{array}{l}\text { Panel A } \\
\text { TSH }(\mathrm{mlU} / \mathrm{l})^{\mathrm{a}}\end{array}$} \\
\hline $\begin{array}{l}\text { Geometrical mean }( \pm \text { S.D. }) \\
\text { TPO-Ab presence }(\%)\end{array}$ & 1.48 & 1.11 & $1.60(1.04-2.47)$ & $0.033^{*}$ & $1.80(1.07-3.03)$ & $0.027^{\star}$ \\
\hline $\begin{array}{l}\text { Positive } \\
\text { Age (year) }\end{array}$ & $0 \%(0 / 27)$ & $5.8 \%(144 / 2465)$ & $0.00(-)$ & 0.996 & $0.00(-)$ & 0.996 \\
\hline $\begin{array}{l}\text { Mean ( } \pm \text { S.D.) } \\
\text { Smoking (\%) }\end{array}$ & $31( \pm 5.5)$ & $32( \pm 4.0)$ & $0.92(0.84-1.00)$ & 0.056 & $0.94(0.86-1.03)$ & 0.199 \\
\hline $\begin{array}{l}\text { Yes } \\
\text { Parity (\%) }\end{array}$ & $19 \%(5 / 27)$ & $9.1 \%(225 / 2465)$ & $2.32(0.87-6.21)$ & 0.094 & $1.96(0.69-5.56)$ & 0.203 \\
\hline $\begin{array}{l}0 \\
1 \\
2+\end{array}$ & $\begin{array}{l}67 \%(18 / 27) \\
22 \%(6 / 27) \\
7.4 \%(2 / 27)\end{array}$ & $\begin{array}{l}60 \%(1467 / 2465) \\
32 \%(778 / 2465) \\
7.0 \%(172 / 2465)\end{array}$ & $\begin{array}{l}\text { Reference } \\
0.63(0.25-1.59) \\
0.95(0.22-4.12)\end{array}$ & 0.616 & $\begin{array}{l}\text { Reference } \\
0.65(0.24-1.74) \\
1.03(0.22-4.96)\end{array}$ & 0.673 \\
\hline $\begin{array}{l}\text { DM } \\
\text { Pre-existent } \\
\text { Gestational diabetes }\end{array}$ & $\begin{array}{l}7.4 \%(2 / 27) \\
0 \%(0 / 27) \\
0 \%(0 / 27)\end{array}$ & $\begin{array}{l}1.0 \%(1 / 2 / 2465) \\
0.3 \%(8 / 2465) \\
0.1 \%(2 / 2465)\end{array}$ & $\begin{array}{l}\text { Reference } \\
0.00(-) \\
0.00(-)\end{array}$ & 1.00 & $\begin{array}{l}1.03(0.22-4.96) \\
\text { Reference } \\
0.00(-) \\
0.00(-)\end{array}$ & 1.00 \\
\hline $\begin{array}{l}\text { Hypertension } \\
\text { Pre-existent } \\
\text { Gestational hypertension }\end{array}$ & $\begin{array}{l}3.7 \%(1 / 27) \\
0 \%(0 / 27)\end{array}$ & $\begin{array}{l}2.8 \%(70 / 2465) \\
9.3 \%(230 / 2465)\end{array}$ & $\begin{array}{l}1.19(0.16-8.89) \\
0.00(-)\end{array}$ & 0.986 & $\begin{array}{l}\text { Reference } \\
1.14(0.15-8.75) \\
0.00(-)\end{array}$ & 0.992 \\
\hline Previous stillbirth/miscarriage & & & & & & \\
\hline $\begin{array}{l}\text { Yes } \\
\text { Previous preterm delivery }\end{array}$ & $22 \%(6 / 27)$ & $19 \%(459 / 2465)$ & $1.25(0.50-3.11)$ & 0.634 & $1.49(0.57-3.90)$ & 0.413 \\
\hline Yes & $7.4 \%(2 / 27)$ & $1.2 \%(30 / 2465)$ & $6.49(1.47-28.66)$ & $0.014^{*}$ & $9.19(1.93-43.82)$ & $0.005^{\dagger}$ \\
\hline 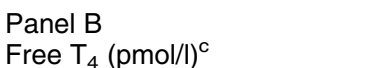 & & & & & & \\
\hline $\begin{array}{l}\text { Geometrical mean } \\
\text { TPO-Ab presence (\%) }\end{array}$ & 9.82 & 9.58 & $2.31(0.37-14.44)^{d}$ & 0.372 & $1.41(0.21-9.40)$ & 0.724 \\
\hline $\begin{array}{l}\text { Positive } \\
\text { Age (year) }\end{array}$ & $0 \%(0 / 27)$ & $5.8 \%(144 / 2465)$ & $0.00(-)$ & 0.996 & $0.00(-)$ & 0.996 \\
\hline $\begin{array}{l}\text { Mean ( } \pm \text { S.D.) } \\
\text { Smoking (\%) }\end{array}$ & $31( \pm 5.5)$ & $32( \pm 4.0)$ & $0.92(0.84-1.00)$ & 0.056 & $0.94(0.86-1.03)$ & 0.158 \\
\hline $\begin{array}{l}\text { Yes } \\
\text { Parity (\%) }\end{array}$ & $19 \%(5 / 27)$ & $9.1 \%(225 / 2465)$ & $2.32(0.87-6.21)$ & 0.094 & $1.95(0.69-5.48)$ & 0.205 \\
\hline $\begin{array}{l}0 \\
1\end{array}$ & $\begin{array}{l}67 \%(18 / 27) \\
22 \%(6 / 27)\end{array}$ & $\begin{array}{l}60 \%(1467 / 2465) \\
32 \%(778 / 2465)\end{array}$ & $\begin{array}{l}\text { Reference } \\
0.63(0.25-1.59)\end{array}$ & 0.616 & $\begin{array}{l}\text { Reference } \\
0.61(0.23-1.62)\end{array}$ & 0.599 \\
\hline$\stackrel{2+}{\mathrm{DM}}$ & $7.4 \%(2 / 27)$ & $7.0 \%(172 / 2465)$ & $\begin{array}{l}0.95(0.22-4.12) \\
\text { Reference }\end{array}$ & 100 & $\begin{array}{l}0.93(0.20-4.44) \\
\text { Reference }\end{array}$ & 100 \\
\hline $\begin{array}{l}\text { Pre-existent } \\
\text { Gestational diabetes }\end{array}$ & $\begin{array}{l}0 \%(0 / 27) \\
0 \%(0 / 27)\end{array}$ & $\begin{array}{l}0.3 \%(8 / 2465) \\
0.1 \%(2 / 2465)\end{array}$ & $\begin{array}{l}0.00(-) \\
0.00(-)\end{array}$ & & $\begin{array}{l}0.00(-) \\
0.00(-)\end{array}$ & \\
\hline $\begin{array}{l}\text { Hypertension } \\
\text { Pre-existent } \\
\text { Gestational hypertension }\end{array}$ & $\begin{array}{l}3.7 \%(1 / 27) \\
0 \%(0 / 27)\end{array}$ & $\begin{array}{l}2.8 \%(70 / 2465) \\
9.3 \%(230 / 2465)\end{array}$ & $\begin{array}{l}1.19(0.16-8.89) \\
0.00(-)\end{array}$ & 0.986 & $\begin{array}{l}\text { Reference } \\
1.28(0.17-9.73) \\
0.00(-)\end{array}$ & 0.973 \\
\hline Previous stillbirth/miscarriage & & & & & & \\
\hline $\begin{array}{l}\text { Yes } \\
\text { Previous preterm delivery }\end{array}$ & $22 \%(6 / 27)$ & $19 \%(459 / 2465)$ & $1.25(0.50-3.11)$ & 0.634 & $1.42(0.54-3.69)$ & 0.475 \\
\hline Yes & $7.4 \%(2 / 27)$ & $1.2 \%(30 / 2465)$ & $6.49(1.47-28.66)$ & $0.014^{*}$ & $8.76(1.83-41.88)$ & $0.007^{\dagger}$ \\
\hline
\end{tabular}

${ }^{*} P<0.05,{ }^{\dagger} P<0.01$

${ }^{\mathrm{a}} \mathrm{TSH}$ is log2 transformed.

${ }^{\mathrm{b}}$ The OR expresses the increase in risk for child loss for every doubling in TSH value.

${ }^{\mathrm{c}}$ Free $\mathrm{T}_{4}$ is log2 transformed.

${ }^{d}$ The OR expresses the increase in risk for child loss for every doubling in free $T_{4}$ value.

had trisomy 16, 18, and 21. One pregnancy was terminated because of the life threatening cardiac pathology and one woman had a fetus with Down's syndrome. These five women were excluded from our analysis since they actively terminated their pregnancy.

We observed a positive linear relationship between the $\log$ transformed TSH values and the risk for subsequent child loss (Fig. 2A). In the univariate analysis, TSH concentration was related to child loss with an odds ratio of 1.60 for every doubling in TSH concentration (95\% confidence interval (CI): 1.04-2.47; $P=0.033$; Table 2). After adjusting for smoking, parity, age, diabetes mellitus (DM), hypertension, previous stillbirth/miscarriage, previous preterm delivery, and TPO-Ab presence in the multivariate model this effect remained with an OR of 1.80 (95\% 

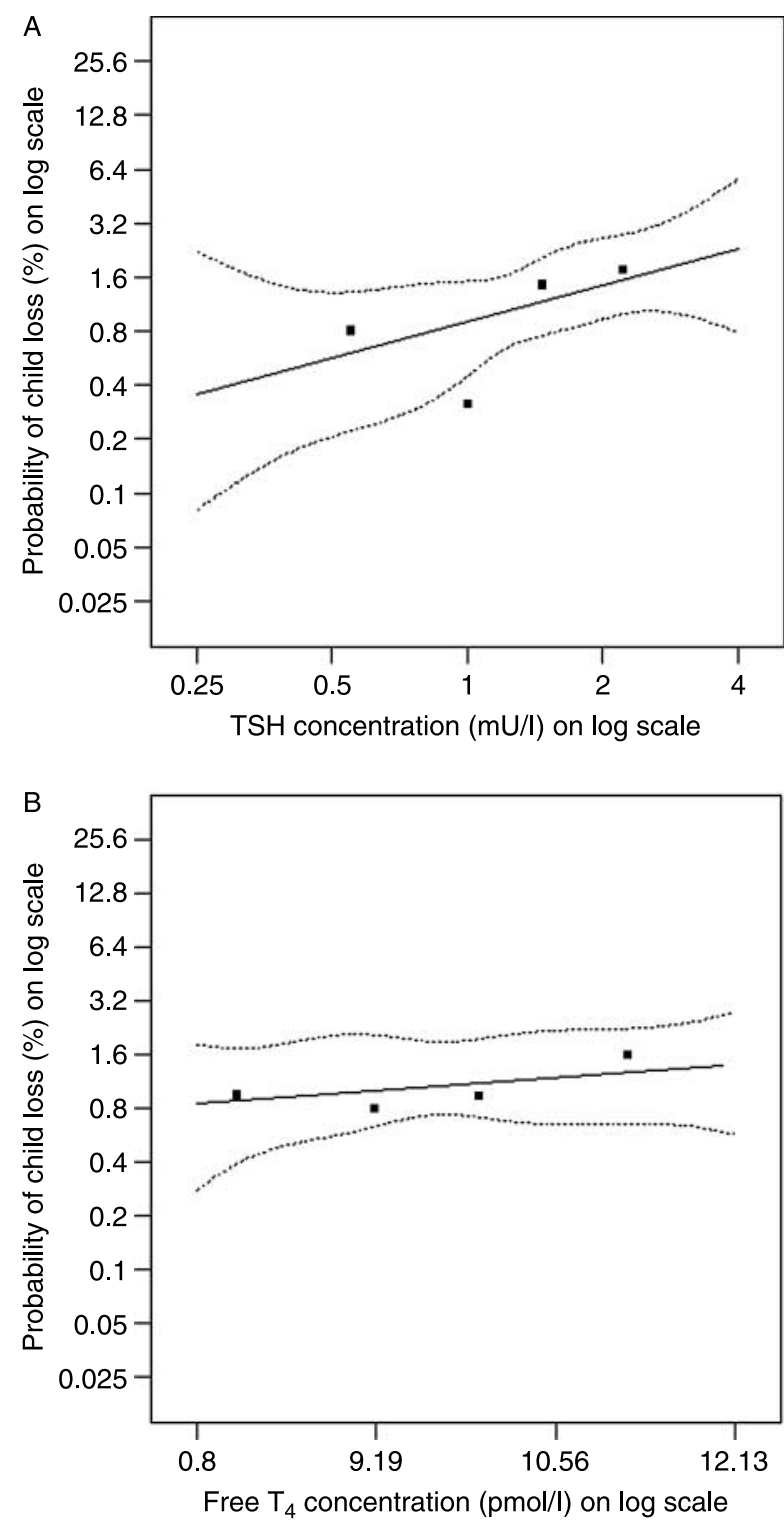

Figure 2 The association between $\mathrm{TSH}(\mathrm{A})$ and $\mathrm{FT}_{4}(\mathrm{~B})$ concentrations and miscarriage, fetal or neonatal death. ${ }^{*} T h e$ linear regression line represents the model based linear line with the 95\% confidence interval of the restricted natural cubic splines (4 knots).

CI: 1.07-3.03; $P=0.027)$. Although the increased relative risk is considerable, the absolute risks are still small. For instance, for a mother with a TSH level of $0.54 \mathrm{mU} / \mathrm{l}$ (10th percentile of study population) the estimated absolute risk would be $0.8 \%$, whereas the expected risk for a woman with a TSH level of $3.13 \mathrm{mU} / \mathrm{l}$ (90th percentile) is $2.2 \%$.

The relationship between $\mathrm{FT}_{4}$ levels and child loss was not statistically significant (Fig. 2B). This was true for both the univariate model with an OR of 2.31 for every doubling in $\mathrm{FT}_{4}$ concentration (95\% CI: 0.37-14.44; $P=0.372$ ) and in the multivariate model after correction for parity, age, smoking, DM, hypertension, previous stillbirth/miscarriage, previous preterm delivery, and TPO-Ab presence in the multivariate model the OR was 1.41 (95\% CI: $0.21-9.40$; $P=0.724$; Table 2).

Of the other factors included in our analysis, previous preterm deliveries was the only other factor next to TSH that was significantly associated with child loss.

\section{Discussion}

This study examined the association between thyroid function ( $\mathrm{TSH}, \mathrm{FT}_{4}$ ) and thyroid autoimmunity (TPO$\mathrm{Ab})$ during pregnancy and the risk of child loss in terms of miscarriage, fetal death or neonatal death in a cohort of Dutch healthy women. The risk of child loss increased significantly with increasing TSH levels during early pregnancy. This effect remained after correction for parity, smoking, DM, hypertension, previous stillbirth/ miscarriage, previous preterm deliveries, and TPO-Ab presence. Surprisingly, no association was observed between $\mathrm{FT}_{4}$ levels and subsequent risk of child loss in these women.

Our data indicate that even in healthy women, without overt thyroid dysfunction, there is an increased risk of miscarriage, fetal death or neonatal death with increasing levels of TSH in pregnancy. The association extended even to pregnant women with TSH values within the normal range, implying a continuous relation between TSH levels and the risk of child loss.

In the study of Allan et al. women with a TSH $>6 \mathrm{mU} / \mathrm{l}$ ( $2.2 \%$ of study population) had a significant increased risk for stillbirth (OR 4.40 (95\% CI: 1.9-9.5)) (11). They did not distinguish between overt hypothyroidism and subclinical hypothyroidism. Nevertheless, our findings are basically in agreement with their study, although we excluded women with overt thyroid dysfunction and examined the association between TSH levels and the risk of child loss in a continuous way. In the study of Casey et al. (2005) who compared 404 women with subclinical hypothyroidism and control group of euthyroid women no excess mortality was observed. However, their study was relatively small, including only two fetal deaths and two neonatal deaths (9).

In search of an explanation of the relation one may consider human chorionic gonadotrophin (hCG); high hCG is associated with low TSH and high $\mathrm{FT}_{4}$ (19). HCG levels are used as markers for miscarriage; women with low hCG levels are at much higher risk of child loss (20). La Marca et al. (1998), however, showed in a casecontrol study that TSH levels are positively associated with miscarriage; this effect was not due to hCG levels since there was no correlation between TSH and hCG levels (20). We did not measure hCG, but confirmed the direct relation between TSH and child loss.

We found no significant effect of $\mathrm{FT}_{4}$ on the risk of child loss, which is in accordance with the study of Casey et al. (2007) where they looked at maternal 
hypothyroxinemia. In their study, they found no adverse effects of low $\mathrm{FT}_{4}$ levels in the presence of normal TSH levels on perinatal outcomes (13).

A number of studies report that women with TPO-Ab have a higher risk of miscarriage (RR ranging from 1.9 to 4.4) than women without TPO-Ab (21-27). In our study, no association between TPO-Ab and child loss was observed, also when considering TPO-Ab as a continuous variable. The discrepancy can be explained by a lack of power, in our study only $5.8 \%$ of the women had TPO-Ab and of these women only $0 \%$ had an adverse pregnancy outcome.

The presence of TPO-Ab is associated with a slightly lower $\mathrm{FT}_{4}$ and higher TSH values, as again observed in our study. The risk for miscarriage in women with $\mathrm{TPO}-\mathrm{Ab}$ decreases upon treatment with levothyroxine, even when pre-treated with $\mathrm{FT}_{4}$ and TSH concentrations which are within the $\mathrm{RR}$ of $\mathrm{FT}_{4}$ and $\mathrm{TSH}$ as demonstrated by Negro et al. (2006) (28). The lower risk of miscarriage via lowering TSH exogenous thyroxine is in agreement with our study findings. The absence of a correlation with $\mathrm{FT}_{4}$ in our study might be due to the much greater sensitivity of TSH to detect small changes in the set point of the hypothalamus-pituitary-thyroid axis compared with $\mathrm{FT}_{4}$ levels.

The large sample size of our study allowed us to demonstrate maternal TSH concentrations as a risk factor for child loss, higher TSH levels throughout the normal RR being associated with higher risk. Because the underlying increase in absolute risk is small, it might be of clinical relevance as active perinatal policies frequently involve avoiding adverse perinatal events which are uncommon in absolute terms (at least in a developed country). It also supports the notion that pregnancy outcome might be improved by treating women with mildly elevated TSH (as in subclinical hypothyroidism) or even with normal TSH (if TPO-Ab are present).

\section{Declaration of interest}

The authors declare that there is no conflict of interest that could be perceived as prejudicing the impartiality of the research reported.

\section{Funding}

This study was supported by a research grant from ZonMw.

\section{Acknowledgements}

We thank the women who participated in the Amsterdam Born Children and their Development study. We also thank all the midwife practices and hospitals in Amsterdam, the Netherlands, for their assistance and data extraction.

\section{References}

1 Glinoer D. The regulation of thyroid function during normal pregnancy: importance of the iodine nutrition status. Best Practice and Research. Clinical Endocrinology and Metabolism 2004 18 133-152.
2 Fantz CR, Dagogo-Jack S, Ladenson JH \& Gronowski AM. Thyroid function during pregnancy. Clinical Chemistry 1999 $452250-2258$.

3 Walker JA, Illions EH, Huddleston JF \& Smallridge RC. Racial comparison of thyroid function and autoimmunity during pregnancy and the postpartum period. Obstetrics and Gynecology 2005106 1365-1371.

4 Glinoer D. What happens to the normal thyroid during pregnancy? Thyroid 1999 9 631-635.

5 Soldin OP, Tracenberg RE, Hollowell JG, Jonklaas J, Janicic N \& Soldin SJ. Trimester-specific changes in maternal thyroid hormone, thyrotropin, and thyroglobulin concentrations during gestation: trends and associations across trimesters in iodine sufficiency. Thyroid 200414 1084-1090.

6 Lazarus JH \& Kokandi A. Thyroid disease in relation to pregnancy: a decade of change. Clinical Endocrinology 200053 265-278.

7 Glinoer D. Pregnancy and iodine. Thyroid 200011 471-481.

8 Pop VJ, Kuijpers JL, Van Baar AL, Verkerk G, Van Son MM, de Vijlder JJ, Vulsma T, Wiersinga WM, Drexhage HA \& Vader HL. Low maternal thryoxine concentrations during early pregnancy are associated with impaired psychomotor development in infancy. Clinical Endocrinology $1990 \mathbf{5 0} 149-155$.

9 Casey BM, Dashe JS, Wells E, McIntire DD, Byrd W, Leveno KJ \& Cunningham FG. Subclinical hypothyroidism and pregnancy outcome. Obstetrics and Gynecology 2005105 239-245.

10 Haddow JE, Palomaki Walter CA, Williams JR, Knight GJ, Gagnon J, O'Heir CE, Mitchell ML, Hermos RJ, Waisbren SE, Faix JD \& Klein RZ. Maternal thyroid deficiency during pregnancy and subsequent neuropsychological development of the child. New England Journal of Medicine 1999341 549-555.

11 Allan WC, Haddow JE, Palomaki GE, Williams JR, Mitchel ML, Hermos RJ, Faix JD \& Klein RZ. Maternal thyroid deficiency and pregnancy complications: implications for population screening. Journal of Medical Screening 20007 127-130.

12 Anselmo J, Cao D, Karrison T, Weiss RE \& Refetoff S. Fetal loss associated with excess thyroid hormone exposure. Journal of the American Medical Association 2004292 691-695.

13 Casey BM, Dashe JS, Spong CY, McIntire DD, Leveno KJ \& Cunningham GF. Perinatal significance of isolated maternal hypothyroxinemia identified in the first half of pregnancy. Obstetrics and Gynecology 2007109 1129-1135.

14 Foundation of Perinatal Registratie Nederland. Perinatal care in the Netherlands. Eds P Offerhaus, A Ravelli \& P Tamminga, Utrecht, Zuidam Uithof Drukkerijen, 2005.

15 Meray N, Reitsma JB, Ravelli AC \& Bonsel GJ. Probabilistic record linkage is a valid and transparent tool to combine databases without a patient identification number. Journal of Clinical Epidemiology 200760 883-891.

16 Benhadi N, Wiersinga WM, Reitsma JB, Vrijkotte TGM, Bonsel GJ \& Van der Wal MF. Ethnic differences in TSH but not in free $\mathrm{T}_{4}$ concentration or TPO-Ab during pregnancy. Clinical Endocrinology $200766765-770$.

17 Durrleman S \& Simon R. Flexible regression models with cubic splines. Statistics in Medicine 19898 551-561.

18 Harrel FE. Regression Modelling Strategies with Applications to Linear Models, Logistic Regression and Survival Analysis. New York: Springer-Verslag, 2001.

19 Glinoer D. Maternal thyroid function in pregnancy. Journal of Endocrinological Investigation 199316 374-378.

20 La Marca A, Morgante G \& De Leo V. Human chorionic gonadotropin, thyroid function and immunological indices in threatened abortion. Obstetrics and Gynecology 199892 206-211.

21 Glinoer D. Editorial: miscarriage in women with positive anti-TPO: is thyroxine the answer? Journal of Clinical Endocrinology and Metabolism 200691 2500-2502.

22 Stagnaro-Green A \& Glinoer D. Thyroid autoimmunity and the risk of miscarriage. Best Practice and Research. Clinical Endocrinology and Metabolism 200418 167-181.

23 Poppe K \& Glinoer D. Thyroid autoimmunity and hypothyroidism before and during pregnancy. Human Reproduction Update 20039 149-161. 
24 Prummel MF \& Wiersinga WM. Thyroid autoimmunity and miscarriage. European Journal of Endocrinology $2004 \mathbf{1 5 0}$ $751-755$

25 Abramson J \& Stagnaro-Green A. Thyroid antibodies and fetal loss: an evolving story. Thyroid 200111 57-63.

26 Glinoer D. Thyroid immunity, thyroid dysfunction, and the risk of miscarriage. American Journal of Reproductive Immunology 200043 202-203.

27 Negro R, Formoso G, Mangieri T, Pezzarossa A, Dazzi D \& Hassan L. Levothyroxine treatment in euthyroid pregnant women with autoimmune thyroid disease: effects on obstetrical complications. Journal of Clinical Endocrinology and Metabolism $2006912587-2591$.

28 Sieiro Netto L, Medina Coeli MC, Michmacher E, Mameda Da Costa S, Nazar L, Galvao D, Buescu A \& Vaisman M. Influence of thyroid autoimmunity and maternal age on the risk of miscarriage. American Journal of Reproductive Immunology $200452312-316$.

Received 9 February 2009

Accepted 3 March 2009 